$$
\text { CONF-960401--35 }
$$

\title{
A Comparison Study On The Densification Behavior And Mechanical Properties of Gelcast Vs Conventionally Formed $\mathrm{B}_{4} \mathrm{C}$ Sintered Conventionally And By Microwaves
}

\author{
P.A. Menchhofer*, M.S. Morrow**, J.O.Kiggans*, D.E. Schechter** \\ * Oak Ridge National Laboratory, Oak Ridge TN., 37831-6087 \\ ** Y-12 Development Division, Oak Ridge, TN., 37831-8096
}

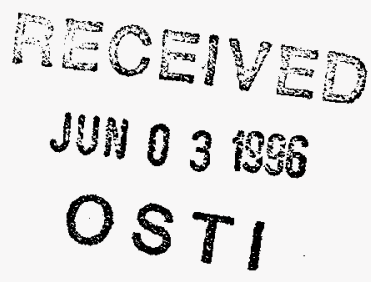

\section{ABSTRACT}

This investigation compares microstructures and mechanical properties of both Gelcast $\mathrm{B}_{4} \mathrm{C}$ and "conventionally" die-pressed $\mathrm{B}_{4} \mathrm{C}$, using both microwave and conventional sintering methods. The microstructures and final mechanical properties of $\mathrm{B}_{4} \mathrm{C}$ specimens are discussed.

\section{INTRODUCTION}

The utilization of microwave energy for reaching high temperatures necessary to densify $\mathrm{B}_{4} \mathrm{C}$ powder is compared with conventional means of sintering by evaluating the mechanical properties after densification. Microwave energy has been shown to be an effective means for achieving high sintered densities, even though temperatures of $-2250^{\circ} \mathrm{C}$ are required. In this study, green preforms of $\mathrm{B}_{4} \mathrm{C}$ specimens were sintered by both conventional and microwave heating. This study also utilized an advanced forming method called "Gelcasting" developed at ORNL"1]. Gelcasting is a fluid forming process whereby high solids suspensions of powders containing dissolved monomers are cast into a mold, then polymerized or "gelled" in situ.

\section{EXPERIMENTAL}

Appropriate amounts of powders were weighed to yield a 50:50 blend of $\mathrm{B}_{4} \mathrm{C}$ (\#3000 and \#1500 powders) ${ }^{\dagger}+5 w t \%$ (Thermax) carbon powder as a sintering aid ${ }^{[2]}$. This $\mathrm{B}_{4} \mathrm{C}$ mixture was first "washed" in methanol, which removes $\mathrm{B}_{2} \mathrm{O}_{3}$ as trimethyl borate ${ }^{[3]}$ which significantly improves the powder dispersion. The methanol treatment of boron carbide powder consisted of the placement of powders in a plastic (HDPE) beaker, then filling remaining volume with methanol to fully cover all powder. This was followed by drying in an oven at $60-70^{\circ} \mathrm{C}$ to evaporate the methanol. This was repeated 3 times for efficacy. Samples of mixed powder were uniaxially cold pressed in stainless steel dies to 15KSI using a light coating of stearic acid as a die lubricant, followed by isostatic pressing at 50KSI.

Gelcasting slurries were prepared using a $15 \%$ aqueous solution of methacrylamide ${ }^{\#}$ : methylbisacrylamide ${ }^{t \dagger}$ (MAM:MBAM at 2.5:1 respectively). The $\mathrm{pH}$ was adjusted to $>11$ using small additives of tetramethyl ammonium hydroxide (TMAH) ${ }^{\dagger \dagger}$. Darvan \# $7^{\dagger f \dagger}$ and PVP K-15 each at $0.5 \%$ by weight of the $\mathrm{B}_{4} \mathrm{C}$ powder were added as dispersants.

$+\quad$ B C from E.S.K. Kempten, Germany (\#3000 and \#1500 powders)

t+ Sigma Chemical Co., St. Louis, MO

t+t R.T. Vanderbilt Company, Inc., Norwalk, CT.

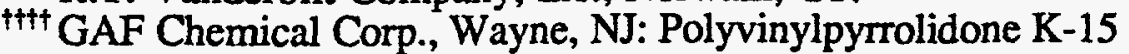

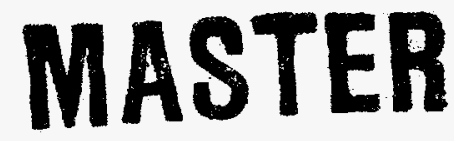

"The submitted manuscript has been authored by a contractor

of the U.S. government under contract NO. DE-ACOS-

$960 R 22464$. Accordingly, the U.S. Government retains a

nonexclusive, royalty-free license to publish or reproduce the

published form of this contribution, or allow others to do so,

for U.S. Government purposes." 


\section{DISCLAIMER}

Portions of this document may be illegible in electronic image products. Images are produced from the best available original document. 
The $\mathrm{B}_{4} \mathrm{C}$ powder was then added to the monomer premix (to yield a solids loading of $45 \%$ by volume) while stirring on a laboratory mixer until fluid. The production of samples was completed as follows: The plastic (HDPE) mold was prepared by spraying with Polyester Parafilm. The $\mathrm{B}_{4} \mathrm{C}$ slurry was degassed on ro-vap laboratory evaporator for $\sim 30$ minutes at approximately $0^{\circ} \mathrm{C}$. (to prevent air entrapment in the finished samples) prior to addition of the catalyst tetramethylethylenediamine ${ }^{\dagger}$ (TEMED) first at the rate 0.1 microliter / gram (of slurry) followed by the ammonium persulfate ${ }^{\dagger}$ (APS). Note, the $\mathrm{pH}$ of the A.P.S. had to be adjusted as follows by: addition of 500 microlitres TMAH/ $25 \mathrm{cc}$ of an aqueous $10 \%$ APS solution. (which increased pH to $~ 8.5$ ). This mixture was then stirred for 1-3 minutes on the Ro-Vap while continuing to degas for $\sim 2$ minutes. The APS was then added at the rate 4 microliters / gram of slurry, with an additional 2 minutes for stirring, before removal and casting. Note, the order of addition was found to be essential to achieve optimal dispersion.

The casting of samples was accomplished simply by pouring the slurry into molds to yield specimens (approximately .5" thick by 2.5 "dia), which were then covered and placed in an oven at $70^{\circ} \mathrm{C}$. Samples were allowed $\sim 60$ mins. for gelation. Specimens were removed from the molds and dried at room temperature. They were debindered in argon (to prevent oxidation and the formation of $\mathrm{B}_{2} \mathrm{O}_{3}$ ) to $600^{\circ} \mathrm{C}$ and were sintered by either conventional or microwave heating. Half of the green preforms were sintered conventionally at $\left(2250^{\circ} \mathrm{C}\right)$ and half by microwave heating (estimated at $2250^{\circ} \mathrm{C}$ ).

After sintering, the densities of samples were measured by the Archimedes method. The sintered samples were then diamond machined and polished. Hardness and toughness measurements were calculated from micro-indents made on the polished samples. Polished samples were then etched using an alkaline electrolytic process and photographed on a Leica Reichert MEF4-A microscope at $1000 \mathrm{X}$ using differential interference contrast to enhance the microstructural features.

\section{RESULTS}

For the $\mathrm{B}_{4} \mathrm{C}$ materials sintered by microwave heating, the die-pressed and the Gelcast materials had comparable densities, with the Gelcast material being slightly higher at $94 \%$ of theoretical. The hardness and toughness values were also comparable. Further sintering studies are being conducted and improved methods for temperature measurement in the microwave cavity are being explored. For specimens sintered conventionally, those produced by gelcasting exhibit improvements in the final properties when compared to samples formed by "conventional" methods. For the B4C samples processed by conventional sintering, the densities were $\sim 8 \%$ higher for those formed by Gelcasting (95\% of theoretical) as compared to die-pressed-isopressed samples, (only $87 \%$ of theoretical density). The higher densities of the sintered gelcast materials resulted in improved mechanical properties.

Densities of the sintered materials are compared in figure 1. Note for all graphs in figures1-4: the specimens A2-A4 were sintered by microwaves, the specimens B1-B2 were sintered conventionally). Hardness and toughness measurements are compared in figure 2. Correlations of density, hardness and toughness are shown in figure 3.

Typical microstructures are presented in figure 4. In the microwave sintering experiments, it was apparent that the expected sintering temperature of $2250^{\circ} \mathrm{C}$ was exceeded, as evidenced by excessive grain growth and crystallographic twinning of some grains ${ }^{[4]}$ (specimens A2,A3,A4 in figure 4). After sintering, the average grain size of samples fabricated by Gelcasting was $\sim 5 \mu \mathrm{m}$ compared to $-10 \mu \mathrm{m}$ for the microwave sintered material. For the specimens sintered conventionally, the Gelcast specimen (B1 in figure 4) exhibited finer grain size, a more uniform microstructure, and improved mechanical properties.

† Sigma Chemical Co., St. Louis, MO. 


\section{CONCLUSIONS}

Although the expected sintering temperature of $2250^{\circ} \mathrm{C}$ was beleived to be exceeded, the densification of B4C by microwave energy is an effective method for densification. As further studies are conducted and improved methods for temperature measurement in the microwave cavity are resolved, it is expected that improvements in mechanical properties will follow. For the comparison of Gelcast vs die-pressing forming processes, specimen formed by Gelcasting exhibited finer grain size, more uniform microstructures, and improved mechanical properties.

\section{REFERENCES}

1. Young, A. C., O.O. Omatete, M. A. Janney, and P.A. Menchhofer "Gelcasting of Alumina" J. Am. Ceram. Soc., 74[3] 612-18(1991)

2. S.L. Dole and S. Prochazka "Densification and Microstructure Development in Boron Carbide" Ceram. Eng. Sci. Proc., 6 [7-8] (1985)

3. P.D.Williams and D.D. Hawn, "Aqueous Dispersion and Slip Casting of Boron Carbide Powder: Effect of ph and Oxygen Content", J. Am. Ceram. Soc.,74 [7] 1614-18 (1991)

4. S.L. Dole and S. Prochazka and C. I. Hejna "Abnormal Grain Growth and Microcracking in Boron Carbide" J. Am. Ceram. Soc., 68 [9] C-235-C-236 (1985)

\section{ACKNOWLEDGMENTS}

Work supported by the U.S. Dept. of Energy under contract DE-ACO5-84OR21400 with Lockheed Martin Energy Systems, Inc.

\section{DISCLAIMER}

This report was prepared as an account of work sponsored by an agency of the United States Government. Neither the United States Government nor any agency thereof, nor any of their employees, makes any warranty, express or implied, or assumes any legal liability or responsibility for the accuracy, completeness, or usefulness of any information, apparatus, product, or process disclosed, or represents that its use would not infringe privately owned rights. Reference herein to any specific commercial product, process, or service by trade name, trademark, manufacturer, or otherwise does not necessarily constitute or imply its endorsement, recommendation, or favoring by the United States Government or any agency thereof. The views and opinions of authors expressed herein do not necessarily state or reflect those of the United States Government or any agency thereof. 
Fig. 1

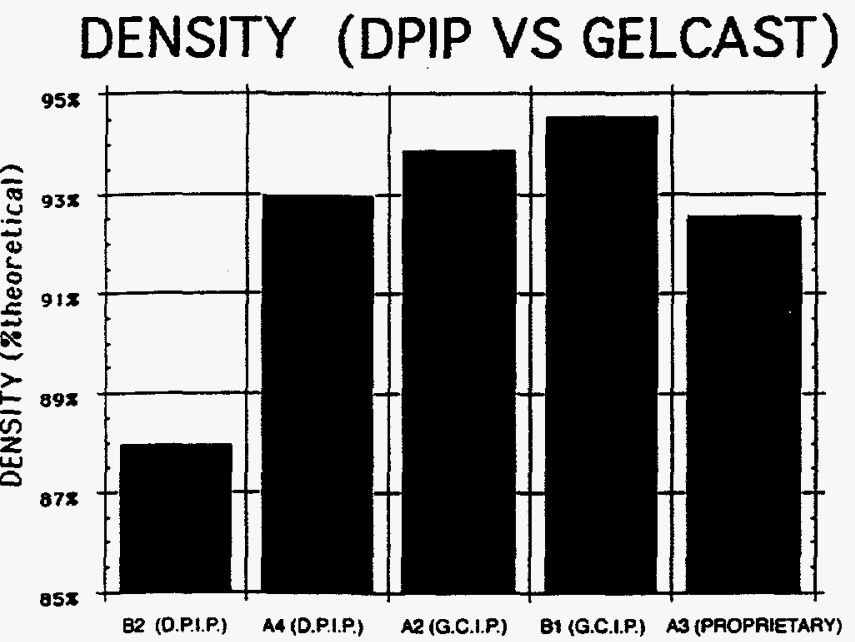

Fig. 1. Density values of die-pressed vs. Gelcast specimens are compared.

Fig. 2

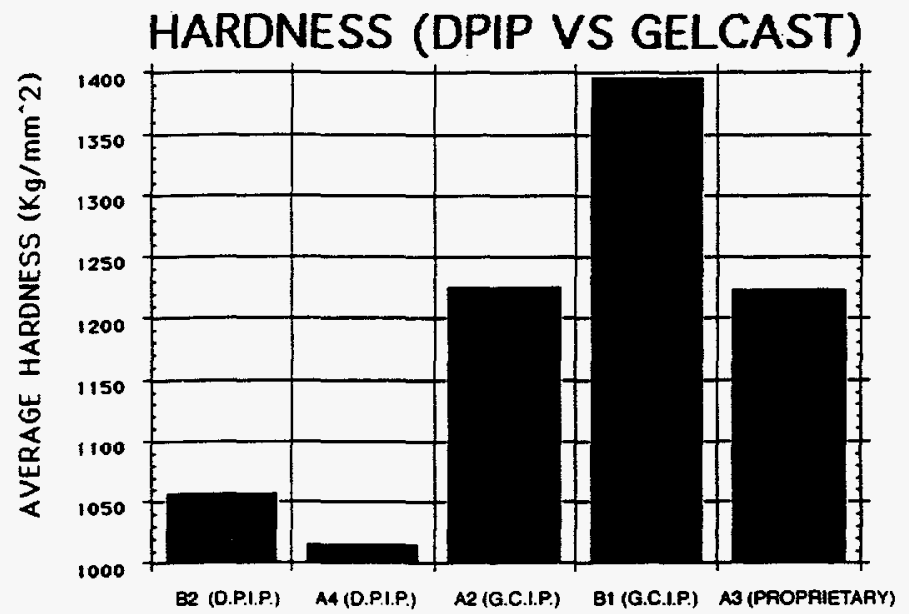

TOUGHNESS (DPIP VS GELCAST)

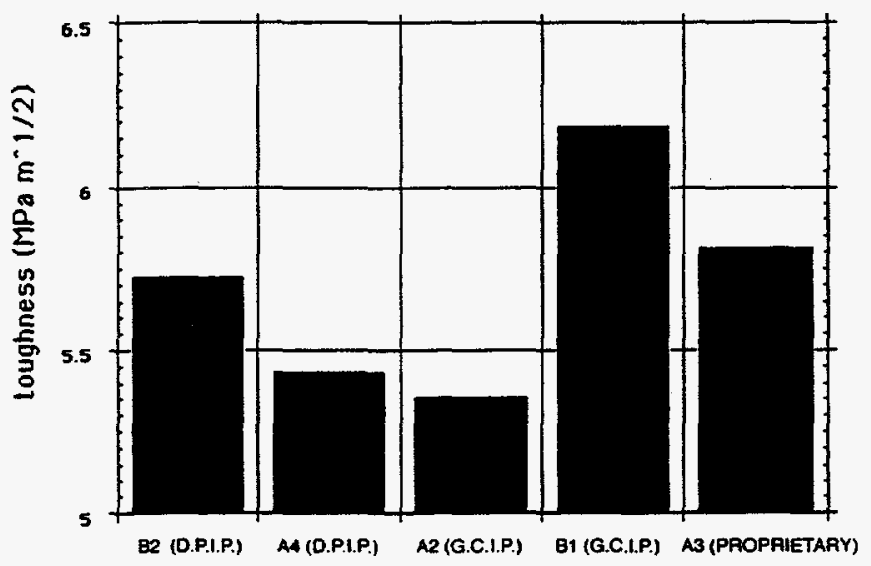

Fig. 2. Hardness and toughness measurements of diepressed vs. Gelcast specimens are compared. 


\section{HARDNESS VS DENSITY}

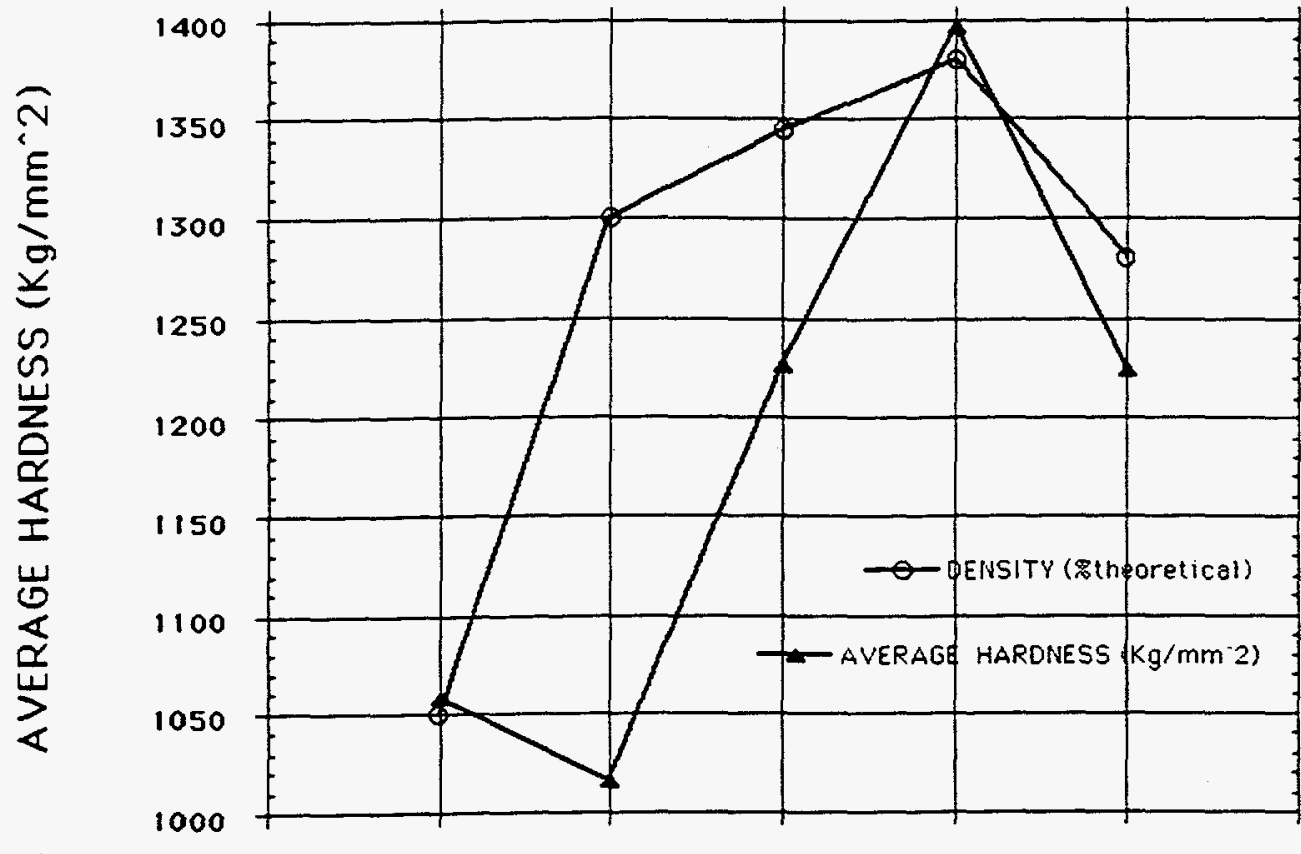

$95 \%$

94\%

$93 \%$

928

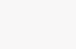

918

$90 \%$

(1)

898

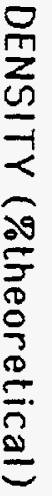

B2 (D.P.I.P) A4 (D.P..P.) A2 (G.C.IP.) B1 (G.C.I.P.) A3 (PROPRIETARY)

88\%

878

HARDNESS VS TOUGHNESS

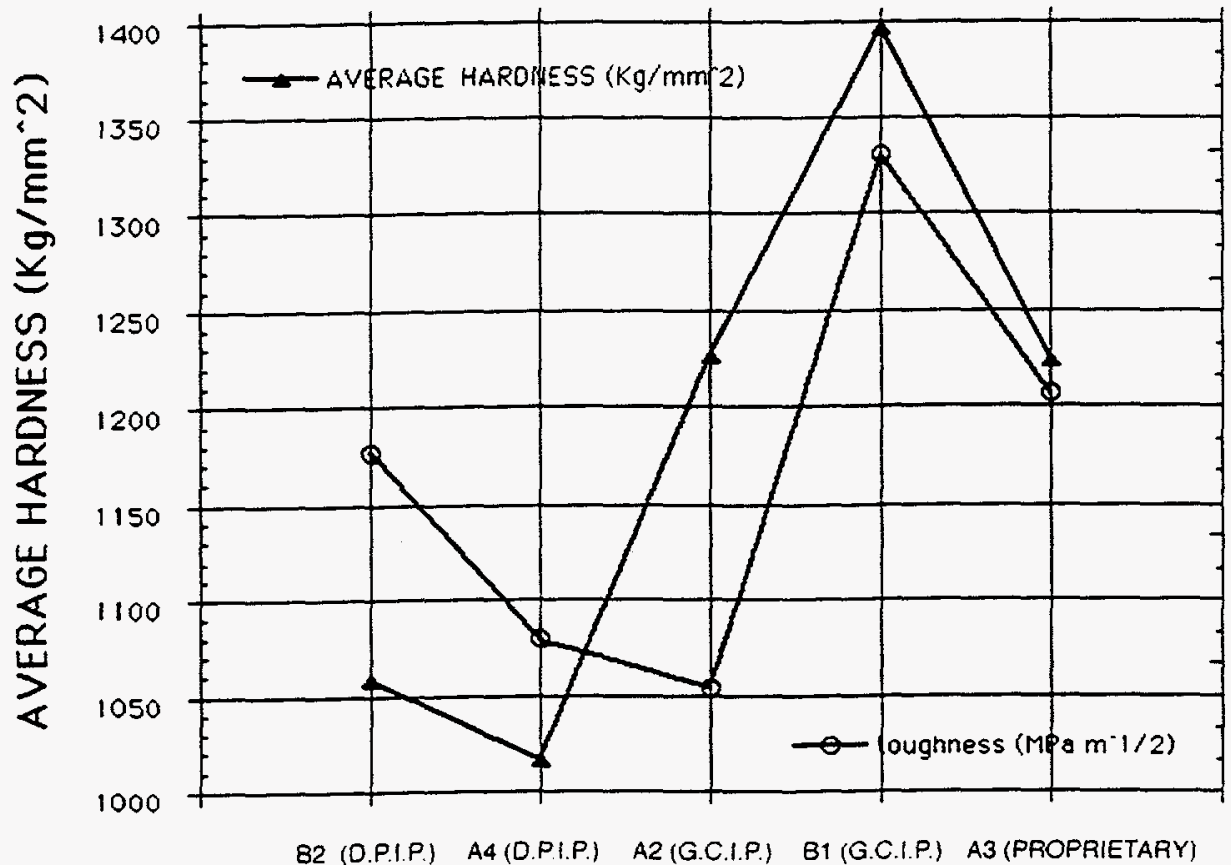

6.4

6.2

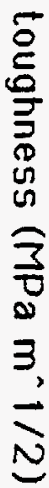

5.4

5.2

Fig. 3. Correlations of density, hardness and toughness values of die-pressed vs. Gelcast specimens are compared.

Fig. 3 


\section{MICROSTRUCTURAL DEVELOPMENT FORMING METHOD}

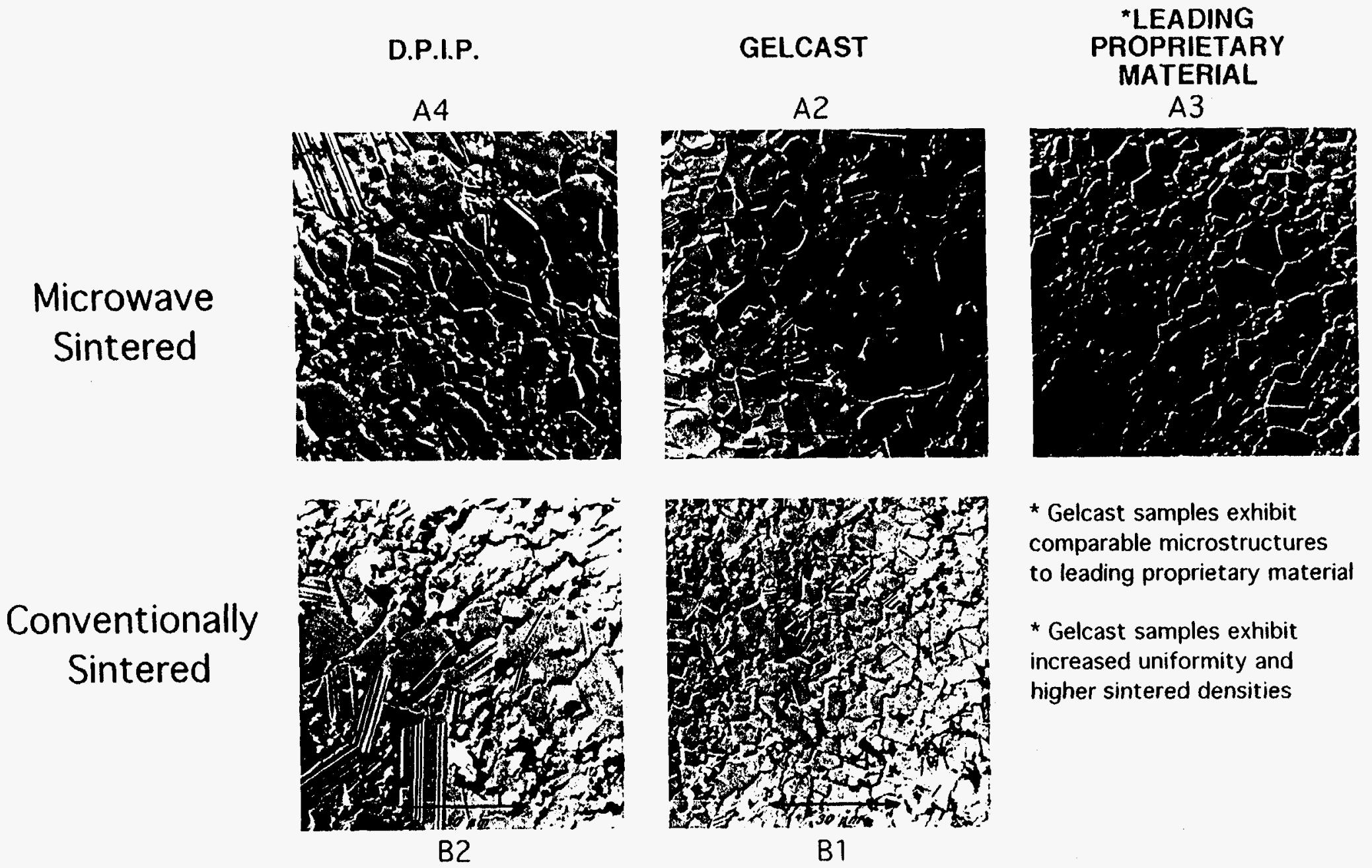

Fig. 4. Microstructures of die-pressed vs. Gelcast specimens are compared.

Fig. 4 